\title{
AVALIAÇÃO DO VOCABULÁRIO EXPRESSIVO EM CRIANÇAS SURDAS USUÁRIAS DA LÍNGUA BRASILEIRA DE SINAIS
}

\author{
Expressive vocabulary evaluation in deaf children users \\ of the Brazilian language of signs
}

\author{
Michelle Imaculada Otaviani Ferreira ${ }^{(1)}$, Sabrina Araújo Dornelas ${ }^{(2)}$, \\ Márcia Miliane Maciel Teófilo ${ }^{(3)}$, Luciana Mendonça Alves ${ }^{(4)}$
}

\begin{abstract}
RESUMO
Objetivo: investigar o desempenho de crianças surdas usuárias da Língua Brasileira de Sinais em teste de vocabulário expressivo. Método: a amostra foi composta por 64 sujeitos (32 crianças no grupo estudo e 32 no grupo controle) que foram divididos em 4 grupos por idade (5, 6,7 e 8 anos). Todas as crianças foram submetidas ao Teste de Linguagem Infantil ABFW - Vocabulário. As respostas foram classificadas em designação do vocábulo usual (DVU), não-designação (ND) e processo de substituição (PS), de acordo com a proposta da autora da prova. Resultados: na maioria dos campos conceituais, o grupo de deficientes auditivos obteve pior desempenho em relação ao grupo controle. Verificou-se que nos dois grupos estudados os piores desempenhos ocorreram nas categorias locais, alimentos e vestuário, em todas as idades. Em ambos os grupos verificou-se melhor desempenho nas crianças de 5 anos de idade, em comparação às demais crianças. Também em ambos os grupos estudados, os processos de substituição foram observados com maior freqüência no campo locais e com menor freqüência em formas e cores. Não houve diferença significante entre as idades. Conclusão: os campos conceituais com maiores índices de acerto nas crianças surdas usuárias da Língua Brasileira de Sinais foram profissões, brinquedos e instrumentos musicais e móveis e utensílios domésticos. Apesar das diferenças quantitativas observadas em relação aos grupos, observouse grande similaridade qualitativa quanto às respostas obtidas, sugerindo-se um processo evolutivo semelhante na aquisição lexical dos grupos.
\end{abstract}

DESCRITORES: Linguagem Infantil; Perda Auditiva; Vocabulário; Linguagem de Sinais

\section{INTRODUÇÃO}

O desenvolvimento da linguagem se dá de forma multifatorial e a informação lingüística pode ser

(1) Fonoaudióloga da Secretaria Municipal de Educação de Nova Serrana, MG; Especialização em Linguagem pelo Centro de Especialização em Fonoaudiologia Clínica CEFAC.

(2) Fonoaudióloga; Especialização em Linguagem pelo Centro de Especialização em Fonoaudiologia Clínica - CEFAC.

(3) Fonoaudióloga da Secretaria de Saúde de Catalão, GO; Especialização em Linguagem pelo Centro de Especialização em Fonoaudiologia Clínica - CEFAC.

(4) Fonoaudióloga; Docente do curso de Fonoaudiologia do Centro Universitário Metodista Izabela Hendrix e do curso de especialização em Linguagem do Centro de Especialização em Fonoaudiologia Clínica - CEFAC BH, Minas Gerais; Mestre e Doutora em Linguística pela Universidade Federal de Minas Gerais.

Conflito de interesses: inexistente obtida pela audição, pelo movimento dos lábios das pessoas, pela leitura e interpretação do contexto a cerca dos aspectos lingüísticos ${ }^{1}$.

Sabe-se que o aprendizado das palavras e sua adequada utilização é um aspecto fundamental do desenvolvimento da linguagem ${ }^{2}$. Para tornar eficaz esse aprendizado vários sistemas cognitivos trabaIham juntos. Alguns destes envolvem a memória e requerem a capacidade para codificar, armazenare acessar sons (ou sinais) e significados ${ }^{3}$.

A construção do vocabulário infantil baseia-se nas experiências da criança e suas relações com a família, com outras crianças e com o ambiente a que estão expostas, sendo que a aquisição e a expansão desse vocabulário dependerão do desenvolvimento lexical e da habilidade da criança para recorrer a seu léxico. $\mathrm{O}$ acesso ao léxico depende 
da pessoa ter a palavra em seu vocabulário e ser capaz de recorrer rapidamente a ele ${ }^{4,5}$.

Diante da importância do aspecto lexical para o desenvolvimento da linguagem, as alterações no processo de aquisição do vocabulário (aquisição lexical) apresentam forte influência no desenvolvimento global lingüístico ${ }^{6}$.

Muitos estudos têm sido realizados no sentido de entender como crianças com desenvolvimento normal de linguagem aumentam seu vocabulário, porém pouco se sabe sobre o processo de aquisição lexical naquelas com alteração ${ }^{7}$. Em relação àquelas com deficiência auditiva, pode-se dizer que há verdadeira escassez de pesquisa nesse sentido.

Muitas vezes, a linguagem é desconsiderada ou desvalorizada na intervenção de crianças surdas ou portadoras de deficiência auditiva, enfatizandose o uso da prótese auditiva, o desenvolvimento da percepção auditiva e o treino intensivo de fala ${ }^{8}$.

Antigamente, o trabalho de intervenção do deficiente auditivo era dirigido para uma "recitação" e não para a aquisição de uma linguagem propriamente dita, o que resultava em um vocabulário limitado e, muitas vezes, sem sentido ${ }^{9}$.

Alguns autores acreditam que a aquisição e o aumento do léxico são prejudicados em função da falta do reforço auditivo em coincidência com os vocábulos que representam os objetos presentes no ambiente das crianças ${ }^{10}$.

Um aspecto importante a se considerar em pesquisas com esta população é o fato de que os surdos utilizam diferentes formas de comunicação. Diante desse fato, surgem diferentes abordagens terapêuticas, principalmente, confrontandose o Oralismo - princípio que visa dar ao surdo a oportunidade para comunicar-se por meio da fala, aproximando-o e integrando-o à comunidade de ouvintes, aproveitando o resíduo auditivo apresentado através de aparelhos e de treinamentos que estimulam a oralidade - e o Bilingüismo - princípio que acredita que os surdos devem adquirir como língua materna a língua de sinais; e como segunda língua, a língua oral oficial de seu país; no caso do Brasil, o português falado e escrito ${ }^{11}$.

Em relação à avaliação do vocabulário (receptivo e/ou expressivo) de crianças com deficiência auditiva, estudos demonstram que quanto maior o grau de perda auditiva, menor o vocabulário receptivo, a consciência fonológica, a discriminação auditiva e a nota escolar, e maior a incidência de dificuldades articulatórias e de trocas e omissões articulatórias ${ }^{12}$. Outro estudo observou que crianças que se comunicam oralmente obtiveram pontuações significantemente mais altas que as crianças que se comunicam por língua de sinais, observando-se uma maior diferença no desempenho do vocabulário expressivo ${ }^{13}$. Em um teste de vocabulário e leitura labial aplicado em crianças e adultos jovens com perda auditiva unilateral severa a profunda em comparação com seus pares sem perda auditiva, observou-se pontuações mais baixas no vocabulário e mais alta na leitura labial ${ }^{14}$. Estudo recente, ao avaliar o vocabulário expressivo em crianças deficientes auditivas oralizadas com idades entre 3 anos a 8 anos e 11 meses verificou que somente as crianças de três anos a quatro anos e onze meses apresentaram proporções de respostas compatíveis aos indivíduos ouvintes da mesma faixa etária ${ }^{15}$.

Esclarecer o padrão de desenvolvimento do vocabulário de crianças surdas nos permite enfatizar os campos conceituais menos conhecidos e direcionar o processo terapêutico. Além disso, observa-se escassez da literatura científica abordando a aquisição e desenvolvimento do vocabulário de crianças surdas usuárias da Língua Brasileira de Sinais (LIBRAS), tornando-se necessários estudos que busquem esclarecer como se dá esse processo já que o vocabulário é um aspecto fundamental para a aquisição e desenvolvimento da linguagem infantil.

Desta forma, o objetivo do presente estudo foi investigar o desempenho de crianças surdas usuárias da LIBRAS em teste de vocabulário expressivo ${ }^{16}$, possibilitando assim, esclarecer o processo de aquisição lexical destas. Os objetivos específicos foram verificar e comparar o desempenho global no teste entre os grupos etários ( 4 anos a 4 anos e 11 meses, 5 anos a 6 anos e 11 meses, 7 anos a 8 anos e 11 meses), comparar os tipos de respostas fornecidas pelas crianças dos diferentes grupos etários em cada campo conceitual, observar os campos conceituais mais afetados nestas crianças e, finalmente, comparar o desempenho destes grupos com o de crianças com desenvolvimento típico de linguagem.

\section{MÉTODO}

Este estudo é de caráter transversal, em que participaram crianças surdas usuárias da Língua Brasileira de Sinais (LIBRAS) - grupo de estudo; e crianças ouvintes - grupo controle; com idades entre 5 e 8 anos.

Os dados do grupo controle foram colhidos em 2 instituições de ensino público regular nas cidades de Catalão (GO) e Nova Serrana (MG); e do grupo de estudo em instituições públicas especializadas no ensino formal da LIBRAS nas cidades de Belo Horizonte e Divinópolis, Minas Gerais.

Foram excluídas do grupo de estudo as crianças não usuárias da LIBRAS, as freqüentes há menos 
de 1 ano em instituição de ensino formal da LIBRAS, as que não se enquadraram na faixa etária de 5 anos a 8 anos e aquelas que apresentaram outras deficiências, além da deficiência auditiva. Em relação ao grupo controle, foram excluídas as crianças que não se enquadraram na faixa etária ou que apresentaram algum tipo de perda auditiva.

Para seleção da amostra do grupo estudo, os dados foram colhidos por meio da aplicação de questionário aos responsáveis pelas crianças nas próprias instituições de ensino. Foram colhidas informações sobre idade, perda auditiva, tempo a que pertence à escola, tipo de comunicação e presença de outras deficiências. Após o levantamento, os pais ou responsáveis das possíveis crianças participantes foram informados da pesquisa, por meio de reuniões, bilhetes e/ou telefonemas, e convidados a permitirem a participação das crianças. Aqueles que concordaram, assinaram o termo de consentimento livre e esclarecido. Em relação ao grupo controle, as crianças foram selecionadas quanto à idade (5 a 8 anos), excluindo-se aquelas com algum tipo de queixa de audição e/ou perda auditiva. Os responsáveis foram comunicados sobre a pesquisa por meio de reuniões e aqueles que concordaram, assinaram o termo de consentimento livre e esclarecido.

Sendo assim, 64 sujeitos participaram da pesquisa, sendo 32 crianças no grupo estudo e 32 no controle.

O teste foi primeiramente aplicado a 5 adultos surdos usuários da LIBRAS, que pertenceram a instituições de ensino de LIBRAS por pelo menos 8 anos, para garantir a fidedignidade dos sinais em LIBRAS dos vocábulos.

As crianças foram encaminhadas, individualmente, a uma sala onde foram submetidas à prova de verificação do Vocabulário, parte integrante do Teste de Linguagem Infantil ABFW ${ }^{16}$. $\mathrm{Na}$ sala, estavam presentes duas das pesquisadoras, uma responsável pela aplicação do teste e outra pela realização da filmagem, uma intérprete de LIBRAS da escola e a criança.

O processo de gravação (filmagem) foi realizado por meio de uma filmadora do modelo GCP-155 Full Auto Compact Camcorder VHS da marca Gradiente e fitas cassetes compactas da marca JVC $\AA$, o que permitiu o registro das respostas.

As respostas foram classificadas em designação do vocábulo usual (DVU), não-designação (ND) e processo de substituição (PS), de acordo com a proposta da autora da prova ${ }^{16}$.

As crianças foram divididas em 4 grupos (5, 6 e 7 e 8 anos) para análise e comparação das respostas.
Este estudo foi aprovado pelo Comitê de Ética em Pesquisa do Centro de Especialização Clínica (CEFAC) sob o parecer de no 016/09.

Para comparação dos resultados entre os grupos de deficientes auditivos e o grupo controle foi utilizado o teste qui-quadrado. Tal teste permite avaliar o relacionamento entre uma variável dependente e outras em nível categórico ou contínuo. Já para avaliar a existência de diferença significante entre os grupos quanto à idade foi utilizado o teste de Kruskal Wallis. Os resultados de ambos os testes são designados pelo $\mathrm{P}$-value e valores inferiores a 0,05 indicam a existência de diferença significante.

\section{RESULTADOS}

Participaram da pesquisa, 64 sujeitos (32 crianças no grupo estudo e 32 no controle). Em relação ao grupo de estudo, foram 11 crianças do sexo feminino e 21 do sexo masculino, sendo $5 \mathrm{com}$ 5 anos de idade, 8 com 6 anos, 7 com 7 anos e 12 crianças com 8 anos. Das 32 crianças, apenas 2 não apresentaram perda pré-lingual (congênita). Todas apresentaram perda auditiva bilateral de grau severo a profundo, sendo a grande maioria neurossensorial. Quando questionados sobre o uso da prótese auditiva, as respostas foram variadas, mas com predomínio do uso freqüente. Em relação à comunicação, a maioria dos sujeitos faz uso da LIBRAS em detrimento do código oral. Já em relação à forma de comunicação que a família usa com a criança observou-se o inverso, sendo o código oral o mais utilizado em detrimento à LIBRAS. A grande maioria já realizou fonoterapia por no mínimo 6 meses. Quanto ao grupo controle, o mesmo foi composto por 13 crianças do sexo feminino e 19 do masculino, sendo 5 crianças com 5 anos, 12 com 6 anos, 6 com 7 anos e 9 com 8 anos.

Inicialmente, realizou-se uma comparação do desempenho dos dois grupos (Deficientes Auditivos $X$ Grupo controle) em todos os campos conceituais (categorias): vestuário, animais, alimentos, meios de transporte, móveis e utensílios, profissões, locais, formas e cores e brinquedos e instrumentos musicais. Nesta análise, baseada no teste quiquadrado (valores P-value inferiores a 0,05 indicam diferença significante entre os grupos em questão), em todas as categorias houve diferença significante entre os grupos, exceto no campo conceitual profissões (Tabela 1).

Destaca-se que na categoria profissões não foram verificadas diferenças significantes entre os grupos de deficientes auditivos e o grupo controle $(P$-value $>0,05)$. O índice geral de acertos foi de $91,8 \%$. 
Tabela 1 - Comparação do desempenho dos dois grupos (deficientes auditivos $\mathrm{x}$ grupo controle) nos campos conceituais

\begin{tabular}{lccccc}
\hline \multirow{2}{*}{ Categorias } & \multicolumn{2}{c}{ Deficientes Auditivos } & \multicolumn{2}{c}{ Grupo Controle } & \multirow{2}{*}{ Valor de P } \\
\cline { 2 - 5 } & \multicolumn{1}{c}{ Alterado } & Adequado & Alterado & Adequado & \\
\hline Locais & $89,7 \%$ & $10,3 \%$ & $50 \%$ & $50 \%$ & 0,001 \\
Brinquedos e instrumentos & $13,8 \%$ & $86,2 \%$ & $0 \%$ & $100 \%$ & 0,030 \\
musicais & $24,1 \%$ & $75,9 \%$ & $0 \%$ & $100 \%$ & 0,003 \\
Móveis e utensílios domésticos & $96,6 \%$ & $3,4 \%$ & $56,2 \%$ & $43,8 \%$ & 0,000 \\
Alimentos & $41,2 \%$ & $58,5 \%$ & $10 \%$ & $90 \%$ & 0,003 \\
Formas e cores & $8,2 \%$ & $91,8 \%$ & $8,2 \%$ & $91,8 \%$ & $>0,05$ \\
Profissões & $37,9 \%$ & $62,1 \%$ & $0 \%$ & $100 \%$ & 0,000 \\
Animais & $48,3 \%$ & $51,7 \%$ & $0 \%$ & $100 \%$ & 0,000 \\
Meios de transporte & $89,7 \%$ & $10,3 \%$ & $37,5 \%$ & $62,5 \%$ & 0,000 \\
Vestuário & & & &
\end{tabular}

Teste qui-quadrado $(\mathrm{P}<0,05$ indicam diferença significante)

Assim, observa-se que na maioria dos campos conceituais, o grupo de deficientes auditivos obteve pior desempenho em relação ao grupo controle, com exceção da categoria profissões.

O campo com pior desempenho em ambos os grupos foi alimentos. O melhor desempenho, no grupo de deficientes auditivos foi obtido na categoria profissões e, no grupo controle, em várias categorias, observando-se $100 \%$ de acerto em brinquedos e instrumentos musicais, animais, móveis e utensílios domésticos e meios de transporte.

Os resultados dos grupos por idade (5 anos, 6 anos, 7 anos e 8 anos) estão descritos na tabela 2 . Para avaliar a existência de diferença significante entre o grupo de deficientes auditivos e o grupo controle, quanto à idade, foi utilizado o teste de Kruskal Wallis. Não houve diferença significante entre as idades, em cada grupo.

Em relação ao grupo de 5 anos, nas crianças deficientes auditivas obteve-se bom desempenho na maioria dos campos conceituais (brinquedos e instrumentos musicais, móveis e utensílios domésticos, formas e cores, profissões, animais e meios de transporte). Entretanto, os campos locais, alimentos e vestuário não obtiveram bons resultados. O mesmo ocorreu nas crianças do grupo controle, com exceção da categoria alimentos, que também se apresentou com bom desempenho.

Tabela 2 - Comparação do desempenho dos grupos por idade nos campos conceituais

\begin{tabular}{|c|c|c|c|c|c|c|c|c|c|}
\hline & & \multicolumn{8}{|c|}{ Idade } \\
\hline & & \multicolumn{2}{|c|}{5 anos } & \multicolumn{2}{|c|}{6 anos } & \multicolumn{2}{|c|}{7 anos } & \multicolumn{2}{|c|}{8 anos } \\
\hline & & $\begin{array}{l}\text { Deficientes } \\
\text { Auditivos }\end{array}$ & Normais & $\begin{array}{l}\text { Deficientes } \\
\text { Auditivos }\end{array}$ & Normais & $\begin{array}{l}\text { Deficientes } \\
\text { Auditivos }\end{array}$ & Normais & $\begin{array}{l}\text { Deficientes } \\
\text { Auditivos }\end{array}$ & Normais \\
\hline \multirow{2}{*}{ Locais } & Alterado & $100,00 \%$ & $80,00 \%$ & $100,00 \%$ & $41,70 \%$ & $100,00 \%$ & $50,00 \%$ & $76,90 \%$ & $44,40 \%$ \\
\hline & Adequado & & $20,00 \%$ & & $58,30 \%$ & & $50,00 \%$ & $23,10 \%$ & $55,60 \%$ \\
\hline \multirow{2}{*}{$\begin{array}{l}\text { Brinquedos e instrumentos } \\
\text { musicais }\end{array}$} & Alterado & & & $25,00 \%$ & & $28,60 \%$ & & $7,70 \%$ & \\
\hline & Adequado & $100,00 \%$ & $100,00 \%$ & $75,00 \%$ & $100,00 \%$ & $71,40 \%$ & $100,00 \%$ & $92,30 \%$ & $100,00 \%$ \\
\hline \multirow{2}{*}{$\begin{array}{l}\text { Móveis e utensílios } \\
\text { domésticos }\end{array}$} & Alterado & & & $25,00 \%$ & & $42,90 \%$ & & $23,10 \%$ & \\
\hline & Adequado & $100,00 \%$ & $100,00 \%$ & $75,00 \%$ & $100,00 \%$ & $57,10 \%$ & $100,00 \%$ & $76,90 \%$ & $100,00 \%$ \\
\hline \multirow{2}{*}{ Alimentos } & Alterado & $80,00 \%$ & $20,00 \%$ & $100,00 \%$ & $50,00 \%$ & $100,00 \%$ & $83,30 \%$ & $100,00 \%$ & $66,70 \%$ \\
\hline & Adequado & $20,00 \%$ & $80,00 \%$ & & $50,00 \%$ & & $16,70 \%$ & & $33,30 \%$ \\
\hline \multirow{2}{*}{ Formas e cores } & Alterado & $20,00 \%$ & & $50,00 \%$ & $66,70 \%$ & $57,10 \%$ & $33,30 \%$ & $23,10 \%$ & $22,20 \%$ \\
\hline & Adequado & $80,00 \%$ & $100,00 \%$ & $50,00 \%$ & $33,30 \%$ & $42,90 \%$ & $66,70 \%$ & $76,90 \%$ & $77,80 \%$ \\
\hline \multirow{2}{*}{ Profissões } & Alterado & & & & $8,30 \%$ & $14,30 \%$ & & $15,40 \%$ & $11,10 \%$ \\
\hline & Adequado & $100,00 \%$ & $100,00 \%$ & $100,00 \%$ & $91,70 \%$ & $85,70 \%$ & $100,00 \%$ & $84,60 \%$ & $88,90 \%$ \\
\hline \multirow{2}{*}{ Animais } & Alterado & $20,00 \%$ & & $50,00 \%$ & & $71,40 \%$ & & $23,10 \%$ & \\
\hline & Adequado & $80,00 \%$ & $100,00 \%$ & $50,00 \%$ & $100,00 \%$ & $28,60 \%$ & $100,00 \%$ & $76,90 \%$ & $100,00 \%$ \\
\hline \multirow{2}{*}{ Meios de transporte } & Alterado & $20,00 \%$ & & $75,00 \%$ & & $71,40 \%$ & & $38,50 \%$ & \\
\hline & Adequado & $80,00 \%$ & $100,00 \%$ & $25,00 \%$ & $100,00 \%$ & $28,60 \%$ & $100,00 \%$ & $61,50 \%$ & $100,00 \%$ \\
\hline \multirow{2}{*}{ Vestuário } & Alterado & $80,00 \%$ & $60,00 \%$ & $100,00 \%$ & $33,30 \%$ & $100,00 \%$ & $33,30 \%$ & $84,60 \%$ & $33,30 \%$ \\
\hline & Adequado & $20,00 \%$ & $40,00 \%$ & & $66,70 \%$ & & $66,70 \%$ & $15,40 \%$ & $66,70 \%$ \\
\hline
\end{tabular}

Teste de Kruskal Wallis $(\mathrm{P}<0,05$ indicam diferença significante) 
No grupo de 6 anos, verificou-se nas crianças deficientes auditivas que apenas 3 campos mostraram-se com boa performance (brinquedos e instrumentos musicais, móveis e utensílios domésticos e profissões), ficando os demais com baixos índices de desempenho. Quanto às crianças do grupo controle, as categorias com bom desempenho foram: brinquedos e instrumentos musicais, móveis e utensílios domésticos, profissões, animais e meios de transporte. Os campos vestuário, locais, alimentos e formas e cores não obtiveram bons resultados.

Nas crianças de 7 anos, observou-se o pior desempenho do grupo de deficientes auditivos, com apenas 2 categorias com bons resultados (brinquedos e instrumentos musicais e profissões). Já no grupo controle, obteve-se o mesmo desempenho observado no grupo das crianças de 6 anos.

Finalmente, quanto às crianças de 8 anos, no grupo de deficientes auditivos, os melhores desempenhos foram nos seguintes campos: brinquedos e instrumentos musicais, móveis e utensílios domésticos, formas e cores, profissões, animais. No grupo controle, verificou-se bom desempenho nos mesmos campos conceituais do grupo de deficientes auditivos, acrescido do campo meios de transporte.
Assim, verificou-se que nos dois grupos estudados (grupo de deficientes auditivos e grupo controle) os piores desempenhos ocorreram nas categorias locais, alimentos e vestuário, em todas as idades. Em ambos os grupos verificou-se melhor desempenho nas crianças de 5 anos de idade, em comparação às demais crianças (Figura 1).

Analisando-se os processos de substituição, observou-se que o campo conceitual com maior freqüência foi locais $e$, com menor freqüência, formas e cores, em ambos os grupos.

Em todas as categorias, o grupo de deficientes auditivos apresentou número maior de trocas do que no grupo controle, com exceção do campo profissões, em que o número de trocas foi distribuído uniformemente entre os dois grupos; e o campo formas e cores, que apresentou número mais expressivo de trocas no grupo controle em comparação com o grupo de DA.

No grupo de deficientes auditivos, as tipologias mais freqüentes foram substituição por designação de funções, substituição por co-hipônimo próximo e substituição por hiperônimo não-imediato. No grupo controle, substituição por co-hipônimo próximo foi a tipologia mais freqüente.

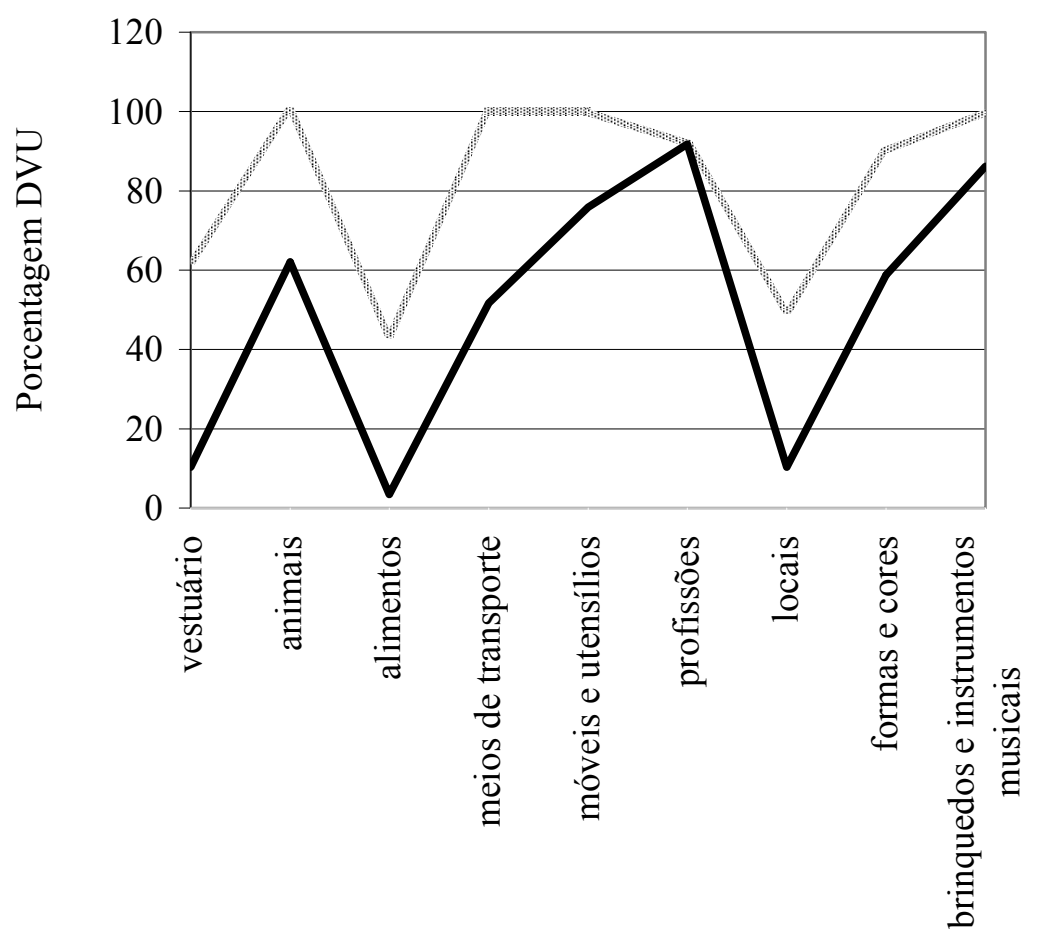

Campo conceitual 


\section{DISCUSSÃO}

Diante dos resultados, observou-se que as crianças deficientes auditivas tiveram desempenho abaixo do esperado para a idade na maioria dos campos semânticos, sendo as categorias locais, vestuário e alimentos as mais prejudicadas. Entretanto, os campos profissões, brinquedos e instrumentos musicais e móveis e utensílios domésticos apresentaram bons resultados. Observa-se que nessas categorias, os sinais utilizados em LIBRAS para designar os itens são sinais bastante funcionais, isto é, realizados por meio das funções de cada objeto. A modalidade manual faz a língua de sinais única em pelo menos um aspecto: é relativamente fácil de usar a modalidade manual para inventar formas de representação que podem ser entendidas imediatamente por quaisquer observadores (por exemplo, gestos indicativos, mímicos ou funcionais) ${ }^{17}$.

Nas crianças do grupo controle, observouse bom desempenho em 6 campos conceituais, estando os demais também abaixo do esperado para a idade (locais, alimentos e vestuário). Assim, em ambos os grupos, essas foram as categorias mais afetadas. Em relação à categoria locais, espera-se que seja uma das mais afetadas em função da necessidade de abstração e representação ${ }^{4,15}$, não sendo o mesmo esperado para os campos alimentos e vestuário.

O baixo desempenho do grupo de deficientes auditivos pode ser explicado pelo fato de a maioria das crianças ter contato com a LIBRAS apenas no ambiente escolar, não sendo a língua reforçada em ambiente familiar. $\mathrm{Na}$ maioria dos questionários aplicados, observou-se que a família comunicase com a criança pelo código oral. Sendo assim, o pouco uso da LIBRAS no cotidiano das crianças pode ter interferido negativamente na aquisição da linguagem em sinais. Estudo recente aponta que o estímulo dado pelas mães às crianças é importante na aquisição lexical ${ }^{4}$.

As experiências com educação bilíngüe no Brasil ainda são restritas. As escolas especializadas no atendimento aos surdos, em geral, contam com professores ouvintes que fazem um uso insatisfatório da língua de sinais. Muito freqüentemente, a língua de sinais é usada como apoio para a linguagem oral e não como uma língua propriamente ${ }^{9}$. Assim, este fator também pode contribuir de forma negativa para aquisição do vocabulário em LIBRAS.

Em estudo realizado com crianças surdas oralizadas (idades entre 3 anos a 8 anos e 11 meses), verificou-se que crianças mais velhas apresentaram melhor desempenho e que aquelas com idades entre cinco a seis anos e onze meses apresentarem desempenho aquém daquelas com três a quatro anos e onze meses. Neste último grupo, observouse desempenho compatível à normalidade, na maioria dos campos conceituais ${ }^{15}$. Neste estudo, observou-se que as crianças da faixa etária de 5 anos obtiveram desempenho compatível à normalidade, na maioria das categorias. Assim, pôde-se observar que em ambos os estudos, os grupos de crianças com menor idade obtiveram desempenho compatível à normalidade. Tal fato pode ser explicado pela intervenção e exposição precoces a partir da modalidade de comunicação escolhida, o que favorece a aquisição lexical. Como se sabe, as crianças deficientes auditivas que recebem intervenção precoce, principalmente durante os primeiros anos de vida, demonstram melhores desempenhos de linguagem do que aquelas estimuladas tardiamente ${ }^{18}$.

Em relação ao grupo controle apresentar melhor desempenho em crianças de 5 anos, acreditase que o estudo possa ter sofrido interferência do tamanho da amostra.

Quanto aos processos de substituição, observou-se maior freqüência no campo locais e menor freqüência em formas e cores, em ambos os grupos. Estes achados vão de encontro à literatura. No campo locais, como dito anteriormente, faz-se necessária maior capacidade de abstração para aquisição dos vocábulos, enquanto que no campo formas e cores, já desde cedo, os vocábulos são ensinados às crianças (formal e informalmente) ${ }^{15}$.

Assim, no presente estudo observou-se que as crianças surdas apresentaram piores resultados em relação às crianças do grupo controle no teste de vocabulário expressivo. Desta forma, os achados concordam com a maioria dos estudos realizados que observaram déficit na aquisição da linguagem em crianças surdas ${ }^{10,12-15}$. Entretanto, pouca importância tem sido dada ao trabalho em linguagem com essas crianças, em detrimento ao treinamento auditivo ${ }^{8,9,11 .}$.

Comparando-se crianças surdas usuárias da LIBRAS e crianças surdas oralizadas observase um desempenho semelhante, visto que fica evidente $o$ atraso na aquisição da linguagem em ambos os grupos.

Neste estudo, apesar do baixo desempenho das crianças surdas em relação ao grupo de crianças ouvintes, verificou-se uma grande simetria de respostas quanto ao resultado observado nas categorias avaliadas. Qualitativamente, pode-se inferir que a evolução da aquisição da linguagem pode estar ocorrendo de forma semelhante nas crianças, já que ambos os grupos apresentaram praticamente as mesmas dificuldades, mesmo que 
quantitativamente diferentes. Crianças expostas a língua de sinais desde o nascimento adquirem aquela linguagem tão naturalmente quanto crianças ouvintes adquirem a linguagem falada a qual elas são expostas, alcançando marcos importantes aproximadamente nas mesmas idades ${ }^{17}$.

Há uma diferença significantemente melhor no desenvolvimento da linguagem de crianças com identificação e intervenção precoces de perda auditiva. Estudos relatam que os seis primeiros meses de vida representam um período sensível para o desenvolvimento da linguagem, ou seja, um período ótimo para se iniciar a intervenção. $O$ acesso à linguagem nesse período representa um ganho, para crianças com perda auditiva significante, em habilidades que geralmente são rebaixadas, quando comparadas às crianças com audição normal ${ }^{19,20}$. Uma criança sem a estimulação adequada antes de seus dois anos de idade pode não atingir por completo seu potencial para função de linguagem ${ }^{21}$. Esta intervenção independe da abordagem terapêutica utilizada, sendo enfocado apenas o período para melhor desenvolvimento.

Deve-se destacar que, sendo a linguagem um bom preditor da inteligência ${ }^{4}$, sua ausência pode provocar um atraso na aquisição de vários aspectos cognitivos ${ }^{11}$. Assim, um trabalho fonoaudiológico voltado para a aquisição lexical, independente da modalidade de comunicação escolhida, propiciará ao surdo um desenvolvimento rico e pleno de linguagem e, conseqüentemente, um desenvolvimento integral.

É importante respeitar a modalidade de comunicação utilizada pelo surdo. Seja ela oral ou língua de sinais, conclui-se que no trabalho realizado com o surdo, o desenvolvimento da linguagem deve ser fortemente enfatizado o mais precocemente possível.
Finalmente, instituições educacionais são de extrema relevância no processo de desenvolvimento da criança, contribuindo tanto para sua educação formal quanto para seu desenvolvimento global ${ }^{4}$. Assim, investimentos nesta área tornamse importantes, especialmente em se tratando da educação de crianças surdas.

\section{CONCLUSÃO}

A partir dos resultados deste estudo, pode-se concluir que os campos conceituais com maiores índices de acerto nas crianças surdas usuárias da LIBRAS foram profissões, brinquedos e instrumentos musicais e móveis e utensílios domésticos.

Em ambos os grupos, as categorias mais afetadas foram locais, alimentos e vestuário. Também em ambos os grupos estudados, os processos de substituição foram observados com maior freqüência no campo locais e com menor freqüência em formas e cores.

No grupo de deficientes auditivos, as tipologias mais freqüentes foram substituição por designação de funções, substituição por co-hipônimo próximo e substituição por hiperônimo não-imediato. No grupo controle, substituição por co-hipônimo próximo foi a tipologia mais freqüente.

Este estudo permite concluir que, apesar das diferenças quantitativas observadas em relação aos grupos, observou-se grande similaridade qualitativa quanto às respostas obtidas, sugerindo-se um processo evolutivo semelhante na aquisição lexical dos grupos.

\section{AGRADECIMENTOS}

Agradecemos a todos que tornaram esta pesquisa possível, em especial à Edilene, Geralda, Ronilza e Poliana. 


\section{ABSTRACT}

Purpose: to investigate the performance of deaf children users of the Brazilian Language of Signs in expressive vocabulary test. Method: the sample was composed by 64 subjects (32 children in the study group and 32 in the control group) that were divided in 4 groups by age (5, 6, 7 and 8-year old). All children were submitted to the Language Test for Young Children ABFW - Vocabulary. The answers were classified in designation of the usual word (DVU), no-designation (ND) and substitution process (PS), in agreement with the author's of the test proposal. Results: in most of the conceptual fields, the hearing loss group obtained worse performance in relation to the control group. It was verified that in both studied groups, the worst performance took place in the categories: places, food and clothes, in all ages. In both groups better performance was verified in the 5 year-old children, in comparison to the other children. Also in both studied groups, the substitution processes were observed with larger frequency in the field places and with smaller frequency in shapes and colors. There was no significant difference among the ages. Conclusion: the conceptual fields with higher success indexes in the deaf children users of the Brazilian Language of Signs were professions, toys and musical instruments and furniture and domestic utensils. In spite of the quantitative differences observed in relation to the groups, great qualitative similarity was observed in relation to the obtained answers, suggesting a similar evolutionary process in the lexical acquisition of the groups.

KEYWORDS: Child Language; Hearing Loss; Vocabulary; Sign Language

\section{REFERÊNCIAS}

1. Hespos SJ. Language acquisition: when does the learning begin?. Curr Biol. 2007;17(16):628-30.

2. Hage SRV, Pereira MB. Desempenho de crianças com desenvolvimento típico de linguagem em prova de vocabulário expressivo. Rev CEFAC. 2006;8(4):419-28.

3. Bloom P. Word learning. Curr Biol. 2001;11(1):5-6. 4. Basílio CS, Puccini RF, Silva EMK, Pedromônico MRM. Living conditions and receptive vocabulary of children aged two to five years. Rev Saúde Públ. 2005;39(5):725-30.

5. Fani Mara Milnitsky FM, Pereira PB, AssencioFerreira VJ, Zorzi JL. Estudo comparativo da linguagem e do vocabulário de crianças que assistem e que não assistem ao programa Castelo Rá-Tim-Bum. Rev CEFAC. 2002;4:229-33.

6. Torres MLGM, Maia HA, Perissinoto J, AssencioFerreira VJ. Descrição do léxico expressivo de crianças aos 5 anos de idade. Rev CEFAC. 2002;4:241-51.

7. Befi-Lopes DM, Gândara JP, Felisbino FS. Categorização semântica e aquisição lexical: desempenho de crianças com alteração do desenvolvimento da linguagem. Rev CEFAC. 2006;8(2):155-61.

8. Dizeu LCTB, Caporali SA. A língua de sinais constituindo o surdo como sujeito. Rev Educ. Soc. 2005;26(91):583-97.
9. Lacerda CBF. A prática pedagógica mediada (também) pela língua de sinais: trabalhando com sujeitos surdos. Cadernos Cedes. 2000;(50):70-83.

10. Azcoaga JE, Bello JA, Citrinovitz J, Derman B, Frutos W. Retardos del lenguaje em el nino. Buenos Aires: Paidós; 1977.

11. Meirelles V, Spinillo AG. Uma análise da coesão textual e da estrutura narrativa em textos escritos por adolescentes surdos. Estud. psicol. 2004;9(1):131-44.

12. Capovilla FC, Prudêncio ER. Teste de vocabulário auditivo por figuras: normatização e validação preliminares. Avaliação psicológica. 2006;5(2):189-203.

13. Eisenberg LS, Kirk KI, Martinez AS, Ying EA, Miyamoto RT. Communication Abilities of children with aided residual hearing. Arch Otolaryngol Head Neck Surg. 2004;130:563-9.

14. Lieu JEC. Speech-language and educational consequences of unilateral hearing loss in children. Arch Otolaryngol Head Neck Surg. 2004;130:524-30.

15. Costa MCM, Chiari BM. Verificação do desempenho de crianças deficientes auditivas oralizadas em teste de vocabulário. Pró-fono $\mathrm{R}$ Atual Cient. 2006;18(2):189.

16. Befi-Lopes DM. Vocabulário (Parte B). In: Andrade CRF, Befi-Lopes DM, Fernandes FDM, Wertzner, HF. ABFW: teste de linguagem infantil e nas a'reas de fonologia, vocabulário, fluência e pragmática. Pró-fono. 2000:41-59. 
17. Goldin-Meadow S. Watching language grow. Proceedings of the National Academy of Sciences. 2005;102(7):2271-2.

18. Geear AE. Speech, Language, and Reading Skills After Early Cochlear Implantation. Arch Otolaryngol Head Neck Surg. 2004;130:634-8.

19. Yoshinaga-Itano C, Sedey AL, Coulter DK, Mehl A. Language of early and later identified children with hearing loss. Pediatrics. 1998;102(5):1161-71.
20. Yoshinaga-Itano C. From Screening to Early Identification and Intervention: Discovering Predictors to Successful Outcomes for Children With Significant Hearing Loss. J Deaf Stud Deaf Educ. 2003;8(1):11-30.

21. Garcia CFD, Isaac ML, Oliveira JAA. Emissão otoacústica evocada transitória: instrumento para detecção precoce de alterações auditivas em recém-nascidos a termo e pré-termo. Rev Bras Otorrinolaringol. 2002;68(3):344-52.

http://dx.doi.org/10.1590/S1516-18462011005000059

RECEBIDO EM: 05/10/2010

ACEITO EM: 25/11/2010

Endereço para correspondência:

Michelle Imaculada Otaviani Ferreira

Rua Carmésia, 1516 - Santa Inês

Belo Horizonte - MG

CEP: 31080-170

E-mail: miotaviani@yahoo.com.br 